\title{
A Pragmatic Function Analysis of the Discourse Marker Anyway from the Perspective of the Relevance Theory in Modern Family
}

\author{
Qing Xue, Da Liu ${ }^{\text {a }}$ \\ Department of Foreign Languages, Liaoning University of Science and Technology, Liaoning, 114051, China \\ a50017352@qq.com
}

Keywords: Anyway, Discourse Marker, Relevance Theory, Pragmatic functions

\begin{abstract}
Discourse markers, as an ordinary accepted linguistic phenomenon, are of great influence for utterances understanding and verbal communication. It helps speakers and hearers make fewer efforts to achieve the most optimal contextual effect. With the development of linguistics, the study of discourse markers has become an important field, which has been developing quickly in recent years.
\end{abstract}

\section{Introduction}

DMs has been attach much more importance in the research of conversation analysis and pragmatics since the 1970s. They convey not the propositional meaning or the semantic meaning. That is to say, they do not constitute the semantic content of discourse, but rather to provide informational mark for the understanding of utterance. As an important cohesive device of discourse coherence, a discourse marker has many pragmatic functions such as restraint, prompt, discourse organization, etc. in communication.

Different linguists have different statement in terms of DMs, Deborah Schiffrin considers DMs as indicators of the location of utterances within the emerging structures, meanings and actions of discourse in the framework of discourse coherence and social interaction, which is called variationist approach. Moreover, some scholars counted DMs as a series of particles playing the role of conjunction in discourse structure, which made great contribution to the utterance production and interpretation. To put it simply, DMs has nothing to do with semantic, but have a connection with the discourse structure.

There is no accurate classification of which words DMs contains; however, since the publication of Cohesion in English (1976, Halliday and Hasan) and Discourse Markers (1987, Schiffrin), many words are established as DMs. They are well, or, and, but, so, because, now, then, you know, I mean, oh, OK, however, anyway, now, all right, by the way, actually. The study of English discourse markers has been penetrated further in recent twenty years. There are three approaches to discourse markers respectively, the coherence-based approach, the grammatical-pragmatic approach and the relevance-theoretical approach. Compared with the other two approaches, Relevance Theory are more suitable for the analyzing of DMs pragmatic function due to its high efficiency and interpret-ability.

It is found that only few articles analyze the pragmatic function of anyway in China National Knowledge Infrastructure, including Li Jing (2012), Ran Haiyong (2012), Ni Fei (2010), Zhai Wenting (2011), Sun Jiali (2013). Therefore, this paper devotes on corpus from the five previous seasons of Modern Family in the hope of helping speakers convey intention and mitigating the information-processed burden of listeners. 


\section{Theoretical backgrounds}

\subsection{A Theory of Relevance}

Relevance Theory gives a feasible solution for the analyzing of DMs pragmatic function. According to Relevance Theory, human communication is a vital activating process, and the topic of utterance is also diverse and constantly changing.

In 1986, Dan and Deirdre Wilson published their book Relevance: Sperber Communication and Cognition in which they propose Relevance Theory(RT). It is a cognitive psychological theory and an inferential approach to pragmatics based on a general understanding of human cognition. RT is expected to give us a satisfactory description of this complex linguistic phenomenon.

It provides a theory of cognitive processes and communication. This theory is the base to account for how utterances are interpreted. It intends not only to answer the philosophical questions about the nature of communication, but also explain how the interpretation process unfolds in the hearer's mind (Wilson 2001).

Ostensive-inferential communication is one of the basic ideas in the relevance theory, and the ostensive-inferential communication model is defined as follows: the communicator produces a stimulus which makes it mutually manifested to both communicator and audience what the communicator intends, by means of this stimulus, to make manifest or more manifest to the audience a set of assumptions. (Sperber \& Wilson, 1995, p.63)

From the discussion above, it is recognized that the correct understanding depends on the identification of speaker's real intentions. Sperber and Wilson $(1986,1995)$ point out that in communication it is essential that hearers recognize Speakers 'intentions to inform them by means of a stimulus. Although different conclusions are likely to be accessed respectively depending on whether the context includes different premises, they are not equally likely to be accessed.

\subsection{A Theory of Discourse Marker}

DMs conveys not the propositional meaning or the semantic meaning. That is to say, they do not constitute the semantic content of discourse, but rather to provide informational mark for the understanding of utterance. As an important cohesive device of discourse coherence, a discourse marker has many pragmatic functions such as restraint, prompt, discourse organization, etc. in communication.

\section{Research Design}

On the basis of the previous studies of DMs, the present research is mainly a combination of quantitative and qualitative study. It aims at the pragmatic functions of the discourse marker anyway mainly in the framework of Relevance Theory. The materials employed have been taken from a concrete corpus of an American comedy TV series, Modern Family (Season 1 to Season 5).

\subsection{Research questions}

The present study concentrates on the following questions in the hope of exploring deeper into the pragmatic functions of discourse marker anyway:

Firstly, what is the frequency of pragmatic functions of the discourse marker anyway in Modern Family?

Secondly, what are the pragmatic functions of anyway and its positions in the sentences?

Thirdly, how does the discourse marker anyway influence the utterance communication from the perspective of Relevance Theory?

Last but not least, what role does the discourse marker anyway play in utterance production and interpretation?

\subsection{Data Collection}

All the data selected have been taken from Modem Family, which is a American comedy TV series 
presenting in a form of Mockumentary. It has won the Emmy Award for Outstanding Comedy Series in each of its first five years and the Emmy Award for Outstanding Supporting Actor in a Comedy Series four times, twice for Eric Stone street and twice for Ty Burrell, as well as the Outstanding Supporting Actress in a Comedy Series twice for Julie Bowen. It has so far won a total of 22 Emmy awards from 75 nominations.

There are three families in Modern Family including traditional and atypical family modes. More significantly, it is Modern Family that provides Chinese audiences with more options to understand all fields of American family life due to its humorous conversations and natural and colloquial language. Furthermore, there are a total of 446,000 words in the script of precious five seasons, which is quite enough in terms of research quantity. Thus, it is true that this program presents abundant and natural corpus in analyzing the discourse markers anyway in details. On the other hand, the script and the subtitles of Modern Family are downloaded from the website (https://www.scriptfly.com/) and the sorting and analyzing of the data are managed manually.

\subsection{Research methodology}

Utmost significance must be attached to statistical data and abundant corpus so as to meet the requirement of this empirical research. Accordingly, this paper devotes on corpus from the five previous seasons of Modern Family in the hope of further exploring the scientific rationality of Relevance Theory model and various pragmatic functions of DMs anyway through providing related supporting evidences.

By applying the search function of Microsoft Office Word 2007, this study analyzes the distributions and occurrence frequencies of the discourse marker anyway. Furthermore, it is pains-taking to sort and analyze data concerning pragmatic functions of DMs anyway, which is less overhead and chance for error. Then, this thesis displays the analysis results with different types of diagram.

By analyzing the data, this thesis uses the Relevance theory as well as the quantitative and qualitative methods. The quantitative method is used to deal with frequencies of anyway as a discourse marker in Modern Family (Season 1-Season 5), which guarantees the objectiveness and reliability of this study. The qualitative method is used to generalize the pragmatic functions of anyway as a discourse marker in the analyzing data, which provides a more detailed and comprehensive analysis. The analysis of the pragmatic functions of discourse marker anyway in the data of Modern Family (Season 1-Season 5) involves the following two stages:

Stage 1: Use the retrieval function of Word 2007 to count the number of anyway in the data of in the data of Modern Family (Season 1-Season 5).

Stage 2: Analyze the pragmatic functions of anyway as a discourse marker from the relevance-theoretic perspective in the data of Modern Family (Season 1-Season 5).

Stage 3: Count the frequency of different pragmatic functions of anyway by using Word 2007.

Stage 1 aims to find out the frequency of anyway as a discourse marker in the data of Modern Family (Season 1-Season 5).

Stage 2 attempts to point out the characteristics of pragmatic functions of anyway used as a discourse marker by the interlocutors in the data of Modern Family (Season 1-Season 5).

Stage 3 is designed to find out the occurrence frequency of various pragmatic function of anyway with detailed supporting data.

\subsection{Results of data analysis}

The following table shows the specific information involved in the study. 
Table 1 Occurrence Frequency of anyway in the previous five seasons in Modern Family

\begin{tabular}{|c|c|c|}
\hline Seasons of Modern Family & Occurrence Frequency of Anyway & Episodes \\
\hline Season 1 & 29 & 24 \\
\hline Season 2 & 20 & 24 \\
\hline Season 3 & 24 & 24 \\
\hline Season 4 & 27 & 24 \\
\hline Season 5 & 24 & 24 \\
\hline
\end{tabular}

From the table above, it can be seen that there are total 120 episodes in the five previous seasons of Modern Family and the occurrence frequency of anyway is 124 . Therefore, anyway occurs average one time an episode.

Table 2 Frequency of pragmatic functions of anyway in Modern Family

\begin{tabular}{|l|l|l|}
\hline Pragmatic Functions & Frequency of Use & Ratio \\
\hline Anyway as a topic-shifting marker & 50 & $40 \%$ \\
\hline Anyway as a conclusion marker & 31 & $25 \%$ \\
\hline Anyway as a accentuating marker & 19 & $15 \%$ \\
\hline Anyway as a supplement marker & 17 & $14 \%$ \\
\hline Anyway as a mitigation marker & 7 & $6 \%$ \\
\hline
\end{tabular}

The table above indicates that, the pragmatic functions of anyway give priority to function of a topic-shifting marker and a conclusion marker, and then the functions of an accentuating marker, a supplement marker and a mitigation marker.

Table 3 Pragmatic functions of anyway and its positions in the sentences in Modern Family

\begin{tabular}{|l|l|}
\hline Pragmatic Functions & The Positions in the Sentences \\
\hline Anyway as a topic-shifting marker & Sentence initial \\
\hline Anyway as a conclusion marker & Sentence initial \\
\hline Anyway as a accentuating marker & Sentence initial/sentence ending \\
\hline Anyway as a supplement marker & Sentence ending \\
\hline Anyway as a mitigation marker & Sentence initial \\
\hline
\end{tabular}

Anyway is an adverb from the angle of word class, but from the viewpoint of its pragmatic functions, especially its connective function, that is anyway is the adverbial conjunction. It can be used in sentence initial and sentence ending for its flexibility. Also, it belongs to Discourse Marker. By concentrating on the scripts of Modern Family (Season1-Season5), this thesis finds out the pragmatic rules as following.

Firstly, it indicates in the table that anyway as a topic-shifting marker is usually in sentence initial and is often used after well to change a new topic of a conversation or respond to the original topic. The example is as following.

(1) Claire: Honey, why do we keep this car?

Phil: It's a classic!

Claire: No, it just sits here. And the seat belts don't work. The doors stick. It leaks fluids. We haven't put fluids in it in 10 years.

Phil: Well, I'm gonna fix all that anyway. And then, uh, it's gonna be Haley's car.

(Modern Family S2 E01)

Furthermore, anyway is often in the sentence initial when it serves as a conclusion marker, which aims to make a summary of the the previous discussions and give the generalization of speaker's intention, and also, aims to repeat and retell something unclear or end the conversation. It is often used after so. Let's come back to one example in Modern Family as following.

(2) Jay: So he's out in our yard and he's got a boombox... What's the name of that movie with the boombox?

Bill: Oh, "Say anything." 
Jay: With John Mahoney. So anyway, he's out there, and he's begging Claire for forgiveness.

(Modern Family S4 E09)

Moreover, when anyway acts as a accentuating marker, it is in either sentence initial or sentence ending for the purpose of strengthening the tone and expressing the strong inner feeling of the speaker.

(3) Claire: How about you make an exception and strap him in there?

Haley: Yeah, we're, like, ten minutes past your deadline, anyway.

Alex: And you don't want to make us angry today.

(Modern Family S3 E17)

Next, serving as a a supplement marker, it is often placed in sentence ending to make sure the hearer can understand the speaker's intention accurately and specifically.

(4) Phil: Can people change? Well, that's a... tough one that's a tough one but I would say "yes", people can change. That's what I believe, anyway. And I will until the day I die.

(Modern Family S1 E13)

Finally, it is often used in the sentence initial as a mitigation marker in a bid to end the embarrassing topic and relieve the tension. To some extent, function of a mitigation marker is subordinate to function of a topic-shifting marker for the consequence of the fact that speaker use anyway to start a new topic to break the ice.

(5) Phil: Honey? Hey. I'm really sorry. That picture was just something that someone sent me. Doesn't matter who. Gil Thorpe. anyway... I don't do that stuff. You're all the porn I need.

(Modern Family S1 E12)

In the above five cases, anyway, serves as the discourse marker, does not constitute the proposition content of utterance and does not affect any truth condition of a discourse. Thus, anyway has distinct pragmatic functions in various situational context.

\section{Five Distinctive Pragmatic Functions of the Discourse Marker Anyway in Modern Family}

Although anyway are of great value in semantic level, this paper focus on the pragmatic functions of anyway based on the five previous seasons of Modern Family, that is, how the discourse marker anyway influences the utterance communication from the perspective of Relevance Theory and what role does the discourse marker anyway play in utterance production and interpretation. In this part, five distinctive pragmatic functions of DMs anyway will be analyzed based on specific corpus from the five previous seasons of Modern Family in the framework of Relevance Theory, which will provide further evidence that Relevance Theory are more suitable for the analyzing of DMs pragmatic function due to its high efficiency and interpret-ability.

\subsection{Anyway as a topic-shifting marker}

Grice hold the view that both parties have the desire to cooperate with each other and to achieve successful communication, which is Cooperative Principle. It is further proposed by Dan Sperber and Deirdre Wilson that every act of ostensive communication is established on the premise of its own optimal relevance and is oriented to establish a general principle of interpreting the inner mechanism of human communication successfully. Consequently, the speaker may use anyway in verbal utterance so as to seek for opportunity of speaking and push discourse change naturally from one to another.

\subsubsection{Function of triggering a new topic}

Human communication is a vital activating process, and the topic of utterance is also diverse and constantly changing. Therefore, the speaker may shift one topic to another by using some linguistic devices. It is put forward by many scholars that discourse marker can realize this interaction transition. Halliday \& Hason hold the view that anyway has the function of leading the end of the last topic by beginning the next new topic, that is "Resumptive Function". Sperber and Wilson argues these shifting markers as the shifting of context markers. 
Anyway is one of DMs that performs this function. On the one hand, the use of anyway not only indicates addresser's intention to start a new topic, but also gives the addressee a reminder or a ostensive stimulus that the following subject will change and then make a preparation for the topic shifting in communication process. On the other hand, as a mitigation and transition marker, anyway makes the transformation of topic are not so towering and ultimately achieve successful communication effect.

In the framework of Relevance Theory, by using anyway, the speaker gives an explicit implication to the addressee so as to improve mutual cognitive environment, and the addressee can infer the speaker's true intentions accurately with the help of context. In this way, the maximum relevance of utterance can be achieved with minimal processing cost. Then, the function of triggering a new topic will be shown in example (6).

(6) Gloria: I was thinking, after lunch, we can go and do a little shopping.

Alex: I'm not getting a dress.

Gloria: I don't care. I'm not your mother.

Alex: I know. You're my grandmother.

Gloria: Step-grandmother. Anyways, today, think of me as a girlfriend... Two girls out for an afternoon of fun.

(Modern Family S1 E03)

This scene in Modern Family introduces that Alex refuses to wear a dress at the wedding of Claire's friend because she doesn't want to look like Haley, and she thinks that Gloria will also force her like her mother. However, Gloria claims that she is not her mother. Then, they have a discussion on grandmother and step-grandmother. It seems that Gloria doesn't want to talk about this topic anymore, so she uses anyway to attract their attention on an afternoon of fun for two girls. In terms of Ostensive-inferential Theory, anyway is used by Gloria for the purpose of showing the intention of trigger a new subject, which can be seen as a ostensive process, while Alex are capable of inferring the willingness of Gloria through anyway, which is a inferential process. Integrating ostensive process with inferential process, utterance communication can push forward naturally.

\subsubsection{Function of responding to the original topic}

Moreover, anyway acts as a maker of returning to an earlier subject, or get to the most interesting point. In interaction, the original subject is usually suddenly interrupted by third parties or other external disturbances, such as a sudden phone call. Because of these external objective reason, sometimes the earlier topic has to be temporarily interrupted, so communicating parties will finish the digression and pursue original subject after clearing the interruption. Let's come back to one example in Modern Family as following.

(7) Phil: All three? What happened? I got you carbon fiber.

Luke: Some kids were messing around with them at school.

Phil: What do you mean? What... what were they doing?

Luke: I don't really want to talk about it.

Phil: You know, I went through that, kids... kids messing with my stuff.

Luke: Really?

Phil: Oh, yeah. In High School, when I first got nominated for junior tumbling congress, my parents had to sign a... release! Anyway, my buddy Dizzy Brindizzi saw it, grabbed it, and made a lot of fun of me. I thought about not going.

(Modern Family S4 E04)

In this case, Phil use the same experience in his High School to comfort Luke, because some kids play tricks on Luke at school. It occurs to Phil that the release and free moment after the signing of written consent. Obviously, it has nothing to with his experience of being teased. By using anyway, Phil returns to the original subject.

To sum up, anyway as a topic-shifting marker is usually in sentence initial and is often used after well to change a new topic of a conversation or respond to the original topic. By anyway, it is easier for communicative parties to seek the process of cognition, inference and mutual manifestation so as 
to acquire the optimal relevance cognitive adjustment in their utterance.

\subsection{Anyway as a conclusion marker}

\subsubsection{Function of summary and induction}

Anyway as a conclusion maker appears in speaker's word and the participant of the conversation, marked the transition to the summary of a section of conversation. The speaker uses the discourse marker anyway as an ostention to give the hearer a summary and generalization of the previous utterances after a detailed account, so that the hearer has the same cognitive context with the speaker. Here is the example to analyze this function.

(8) Jay: 'Cause, you know, I had my share of fights in my time. You know that. Mmm! Mm. Mm. It's too warm for me. Yeah, I remember this time I was crossing the street with Dede, and some jackass almost clipped her. I had the guy on the ground, my foot on his neck, before the car stopped moving.

Manny: Yeah, we've heard all those stories. Maybe my mom wouldn't mind a glimpse of that Jay. That's her. She wants me to help pick out Cam's gift.

Jay: I'm still that guy, you know. 100\%. What the hell? How do you cut your finger on a cracker? anyway, if I thought there was a fight worth fighting, I'd fight it. Ow! Now I got salt in this. That stings!

(Modern Family S3 E17)

This scene in Modern Family introduces that Gloria quarrels with a guy and pushes Jay into a fight with him, but Jay doesn't do it. After back home, Jay provides details of a fight in his early days to Manny, then he uses anyway to draw a conclusion that he only fights for the worthwhile things. Anyway is the same as “总之”in Chinese under this circumstance.

\subsubsection{Function of conversation ending}

There must be an end in the conversation. Therefore, as a conclusion marker, anyway is often used by speaker to give the addressee a ostensive stimulus that he or she will end the utterance. The use of DMs anyway is an explicit ostensive act, followed by a direct ending. It helps the hearer resort to a minimum effort to acquire the speaker's willingness. Then, the function of conversation ending will be shown in example (9).

(9) Ben: Mr. Pritchett? Ben. Ben Dugan. I went to High School with Mitch. We were in the drama club together.

Jay: That's right. Yeah. Geez, I didn't recognize you without that old-guy makeup on. You know, you and Mitch knocked "the sunshine boys" out of the park.

...

Jay: How about you?

Ben: Still acting.

Jay: Fantastic.

Ben: Actually, it's exciting. I'm in a new movie... "Maple drive"... just came out.

Jay: You're kidding me. Look at me... I know somebody famous.

Ben: Uh, anyway, I got to go. Great to see you.

Jay: Good to see you, too.

(Modern Family S1 E21)

In this case, Jay encounters a friend of Mitchell, Ben Dugan and knows that he is still a actor. After the short reminiscing, Ben seems to have something else to do, so he uses anyway to end the conversation.

\subsection{Anyway as a accentuating marker}

In social intercourse, the addresser and the addressee are capable of establishing mutual understanding based on the common assumption, whereas the addressee may not understand the addresser's intention accurately by using the shared assumption in actual verbal interaction. 
Therefore, the addresser attempts to draw addressee's attention by using anyway in a bid to avoid misunderstanding and get the right inference of the utterances by accentuating and reminding, when addresser finds that some kind of ambiguity may encounter to the addressee in their conversation. Other discourse markers like especially, what I mean is, above all, actually, and in Chinese “尤其”, “我是这么看的”, and “我想说的是”, are also serving as a accentuating marker. By anyway, the hearer is able to deduce the intention of speaker to a great extent and get the optimal relevance more easily by the adjustment of cognitive context, which can reduce the processing effort the hearer needs during the inference process.

\subsubsection{Function of emphasize the following content}

As for pragmatic function of an accentuating marker, it refers to anyway as a ostensive stimulus to let the hearer attach much more significance to the content after anyway compared with the content before anyway. Usually in this case, anyway is used in sentence initial. Among other things, Owen considered this pragmatic function as "setting aside a prior assumption" and Altenberg called anyway as "unrestricted concession". Next, accentuating function of anyway will be illustrated in the following supporting data.

Cameron: I have been hired to sing at a wedding this weekend. I was plucked from obscurity after a particularly stirring karaoke performance. So I guess you could say I'm a professional singer now.

Mitchell: I don't know. Well, they're paying you in flowers, so...

Cameron: I would have blown the money on flowers. Anyway, they're saving me a step. Plus, all the great divas are rewarded in flowers.

Mitchell: They're also given paychecks.

(Modern Family S1 E24)

Cameron considers himself as a professional singer after a particularly stirring karaoke performance. However, Mitchell doesn't think so because Cameron only earns flowers instead of money. Then, Cameron uses "anyway" to emphasize that he will use that money to buy flowers even if people pay the cash and people do him a favor by paying him flowers. Here, anyway is used in sentence ending let the hearer attach much more significance to the content after anyway compared with the content before anyway.

\subsubsection{Function of strengthening the tone}

Another case is that anyway is used in the sentence ending to emphasize what the speaker has said in the foregoing utterances and strengthen the tone. There are many scholars studying the emphasizing function of anyway in their papers and articles.

Jay: Hello, ladies.

Kathy: Not interested.

Jay: Wow. I just said hello.

Kathy: We're just kind of having a girls' night.

$\cdots$

Jay: For your information, I'm married to a gorgeous woman.

Phil: Dad, Jay and I are gonna grab a drink from the bar.

Frank: Sure.

Jay: I think I have a picture of her here on this somewhere.

Phil: Let's go, Jay.

Jay: Yeah, she won beauty pageants. Okay. I'm a catch.

Phil: Let's get out of here. This place is dead, anyway.

(Modern Family S5 E06)

Jay, Frank and Phil tries to accost Marcy and Kathy at the bar. However, Kathy does not show any interest to talk with them in a girls' night and are indifferent to Jay. Jay needs his dignity back and wants to prove that he is catch by presenting Kathy the photo of his gorgeous wife. Therefore, Phil emphasize that they must get out of that place for the reason that it is so embarrassing there and use anyway to strengthen the tone to express his strong eager to get out of the awkward moment. In this 
case, anyway is in the sentence ending and acts as a ostensive and reminding stimulus to Jay to leave quickly. Furthermore, Jay can infer the intention of Phil through anyway. Thus, the usage of anyway can help the hearer acquire the optimal relevance and save the hearer's processing effort to yield the implicature.

\subsection{Anyway as a supplement marker}

In communication process, it is common that the speaker may not express his or her intentions clearly or some parts of utterances are rather obscure for sake of the hearer, so further explanation is needed, and discourse marker often performs as a supplement marker in this circumstance. Halliday and Hasan consider this pragmatic function as additive markers, which connect discourse and add new information to preceding information to make written or spoken discourse more coherent. Anyway indicates speaker's intention to further explain or support the previous utterances in which their real ideas or intentions are not conveyed to the hearer, so that hearers can add the new information to his old assumptions and make interpretations in a more explicit and easier way. In this case, anyway, as a supplement marker, is in the end of the sentence. Let's look at the following example in Modern Family:

Lily: Oh, no! You broke Beatrice. Now she can't feed the dolphins.

...

Phil: Okay. Hold on. Here we go. Give me some. Give me some. Give me some. Oh! Let me buy Lily a new doll. It's my fault Cam fell.

Mitchell: No, no need. Uh, the My sweet companion store actually has a hospital with an on-call doctor.

Phil: Well, I can go. I'm taking the girls to the mall anyway.

Cameron: Oh, that's be great. Yeah. And don't worry. She has medical insurance.

(Modern Family S3 E16)

Because Lily gets all the attention of the family that used to belong to Luke, Luke makes a trap so that he can take her down, but Cam accidentally takes a tumble and Lily's doll is broken. Phil thinks that he is responsible for Cam fell, so he wants to buy Lily a new doll. Mitchell refuses it, and then Phil further explains that he can go for the reason that he also needs to take Alex and Haley to the mall.

Therefore, speakers often use discourse marker anyway to improve communicative processes by means of explaining and supplementing.

\subsection{Anyway as a mitigation marker}

There are many face threatening acts in speech communication, for example, the speaker and hearer have disagreement with each other, or the speaker's request is rejected by the hearer. In order to maintain harmonious interpersonal relationship, communication parties will resort to certain linguistic means to keep faces of both parties (at least mitigate the face threat), show politeness, relieve tension and avoid verbal conflict. Some Vague language and direct speech acts performs this function of facilitating interaction and easing face threats by minimizing the potential for conflict, such as: I guess, I am not sure, Could you help me with this? In addition, some discourse markers like anyway also serves as a means of a mitigation marker. It is good at protecting listener's face, so it has a good function of coordinate interpersonal relation. The detailed illustration of this function will be given in example.

Claire: hey. Hi. Sorry. I'm Claire. It's my first day, so I thought I'd say hi.

Staff A, B and C: Oh. Hey. Hi

Claire: Amazing. You guys are actually hanging out by the water cooler.

Staff A: I have xerostomia. It's chronic dry mouth.

Claire: I'm so sorry. I-I-I-I was just doin' a thang, you know, like...Anyway, um...My door's always open... To everyone.

Staff B: That's pritchett's daughter.

Claire: Um, yeah, but I don't want you to think of me like that. I'm -- I'm a friend. I'm a colleague. 
I'm just like you. I'm Claire, you know -- worker bee, just...Great to meet you. Sorry to interrupt, and see you around.

(Modern Family S5 E02)

In this case, after a 20-year vacation, Claire is rejoining the work force and starting a job at her dad's closet company. Claire does want everyone to like her and to be a different manager. Therefore, she tries to communicate with her colleagues, but she chooses a inappropriate subject, and one of the staff may misunderstands her intention and explains that he has chronic dry mouth. Claire feels sorry to be offensive. At the same time, because they are not familiar with each other and lack of common languages, Claire doesn't know what to say and tries to find a topic, then anyway is used to mitigate the face threat and ease the embarrassing issue, so as to achieve optimal contextual effect.

\section{Conclusions}

As DMs are often used in verbal communication. In the past decades, many scholars focus on them from different perspectives, mainly including syntactic-pragmatic perspective, semantic-pragmatic perspective and relevance-theoretical perspective. As for this thesis, it firstly gives a review of DMs study at home and abroad and then from the perspective of Relevance Theory. Secondly, through analyzing the data in Modern Family, the occurrence frequencies of anyway is clear, which is in accordance with the using frequency of anyway in real life. Finally, five pragmatic functions of anyway are revealed in this thesis on the basis of corpus from the previous five seasons of Modern Family, such as the topic-shifting marker, the conclusion marker, the accentuating marker, the supplement marker and the mitigation marker.

The research on native English speakers' use of DMs can not only helps the second language learners to obtain the true intention and meaning of speakers accurately and efficiently, but also avoids embarrassing misunderstandings or even conflicts. Finally, with regard to the findings, this thesis provides some tentative teaching implications, which can enhance the accuracy of second language learners' use of discourse markers in English listening and speaking.

\section{Acknowledgements}

This work was supported by 2017 Education and Reform Project of Liaoning University of

Science and Technology: The Research of "Internet+Manager" Individualized Teaching Mode of University XJGYB201703.

\section{References}

[1] Blakemore, D. (2002). Relevance and Linguistic Meaning: The Semantics and Pragmatics of Discourse Marker. Cambridge: Cambridge University Press.

[2] Blakemore, D. (1987). Semantic Constraints on Relevance, Oxford: Blackwell.

[3] Schiffrin \& Deborah. (1987). Discourse Markers [M]. Cambridge: Cambridge University Press.

[4] Sperber, D\& Wilson, D. (1986). Relevance: Communication and Cognition (1st edition) [M]. Cambridge: Harvard University Press. 